\title{
CENÁRIO PÓS- IMPLANTAÇÃO DO SOFTWARE KOHA NO COLÉGIO PEDRO II
}

Scenario after implementation of koha software in Colégio Pedro II

\section{Márcia Feijão de Figueiredo}

Doutoranda e Mestre em Ciência da Informação (PPGCI IBICT/UFRJ-ECo). Bibliotecária-documentalista no Colégio Pedro II.

marciaffigueiredo@gmail.com

\section{Lehy Chung Baik Torquato}

Especialista em Gestão Eletrônica de Documentos. Bibliotecária-documentalista no Colégio Pedro II. lehybaik@gmail.com

RESUMO: Apresenta um relato de experiência após a etapa de implantação do software Koha no Colégio Pedro II. Descreve o Colégio Pedro Il e suas características, o software Koha e o início da etapa de alimentação, quais situações ajudaram a aumentar a inserção de dados e as circunstancias que atrapalharam o início em alguns campi. Aponta o estado atual de implantação, onde boa parte dos campi caminham para a automação dos produtos e serviços e os problemas que impedem melhor êxito nas atividades. Como perspectiva para o futuro, defende a inserção de recursos para aquisição de materiais, atualização de alguns serviços realizados pela DTI e buscar ações para ajudar os campi estagnados a iniciarem a alimentação dos dados e o uso do módulo circulação.

PALAVRAS-CHAVE: Colégio Pedro II. Open Source. Gerenciamento Eletrônico de Bibliotecas. Koha.

ABSTRACT: It presents an experience report after the implementation stage of the Koha software in Colégio Pedro II. Describes the Pedro II College and its characteristics, the Koha software and the beginning of the feeding phase, which situations helped increase the insertion of data and the circumstances that hindered the beginning of some campuses. It points out the current state of implementation, where most of the campuses are moving towards the automation of products and services and the problems that prevent better success in the activities. As a 
perspective for the future, it advocates insertion of resources to acquire materials, update some services performed by the DTI and seek actions to help stagnant campuses start to feed data and use the circulation module.

KEYWORDS: Colégio Pedro II. Open Source. Information Library Sistem. Koha.

\section{Introdução}

A adoção de softwares open source de Sistemas Integrados de Gestão de Bibliotecas - SIGBs para automação tem sido cada vez mais cogitado por instituições para suas unidades de informação. As motivações são diversas, desde a falta de recursos financeiros para aquisição e manutenção de softwares com licença proprietária até a necessidade de autonomia para o gerenciamento pleno dos módulos, onde é possível vislumbrar projetos de integração com outros sistemas de informação.

No Brasil, a divulgação do Software internacional Koha aumentou quando o Instituto Brasileiro de Informação em Ciência e Tecnologia - IBICT começou a fomentar seu uso em 2015 através de algumas ações, como a colaboração na implantação do SIGB na Biblioteca da Secretaria Nacional da Juventude ${ }^{1}$, a criação de uma Wiki² brasileira e do Guia do Usuário do Koha em versões impressa e ebook (SCHIESSL, 2017).

O Colégio Pedro II iniciou o projeto de automação em 2014, quando instalou o Koha no servidor de homologação para análise e testes dos módulos (FIGUEIREDO, 2015). Em setembro do mesmo ano, o Koha é oficialmente adotado como o SIGB para bibliotecas e a partir desse momento a Diretoria de Tecnologia da Informação - DTI, em parceria com a Seção de Bibliotecas, começa a instalar e realizar as parametrizações básicas no servidor definitivo, chamado de Koha produção. Em abril de 2015, o Koha produção está em condições de iniciar a automação e, durante toda a primeira etapa, busca-se as estratégias de implantação sustentável para garantir que a alimentação de dados e uso dos módulos tenha o mínimo de erros possíveis (FIGUEIREDO; TERRA, 2016).

Após mais de dois anos de uso do Koha produção, é possível analisar e apontar como as etapas de alimentação dos dados e uso para as atividades rotineiras das bibliotecas no Colégio Pedro II se desenvolveram. Nesse período algumas bibliotecas conseguiram se tornar totalmente automatizadas, isto é, conseguem

1 OPAC disponível em: http://bibliotecajuventude.ibict.br/cgi-bin/koha/opac-main.pl Acesso em: 06 nov. 2017

2 Disponível em: http://wiki.ibict.br/index.php/Koha Acesso em: 28 ago. 2017. 
realizar todas as atividades pelos módulos disponíveis, mas algumas projeções desejadas no início ainda não se concretizaram e outras bibliotecas, por sua vez, estão muito aquém do proposto.

Assim, esse artigo se propõe a descrever o cenário de uma instituição que adota o Koha como um SIGB open source para bases multicampi, no intuito de atender o Sistema de Bibliotecas, Mediatecas e Salas de Leitura. A análise pósimplantação, onde desde julho de 2015 começou o uso efetivo até o presente momento pode contribuir para quem está na etapa de análise de softwares, seja de licenças proprietárias ou livres/grátis, e deseja compreender como se efetiva o uso, ou seja, a realidade de um SIGB na prática após as fases mais decisivas para a implantação, onde fatores essenciais como estrutura de tecnologias de informação (servidores e equipamentos), parcerias com outros profissionais e setores e engajamento das equipes podem fazer o projeto fracassar ou se consolidar.

O Koha é o software que fundamenta o Catálogo Imperador, ou seja, todo o acervo do Sistema de Bibliotecas, Mediatecas e Salas de Leitura. Ao pensar o cenário pós-implantação, é possível restabelecer as demandas e planejar junto às equipes e a DTI quais são os trâmites prioritários e um planejamento para que a automação do Sistema de Bibliotecas alcance a proposta inicial, ou seja, que todas as unidades de informação consigam utilizar o Koha de modo pleno. Esse relato se propõe a refletir esse momento de estabilização do projeto de automação.

\section{Implatanção do Koha no Colégio Pedro Il: o cenário inicial}

\subsection{O Colégio Pedro II}

Para que o projeto de automação do Sistema de Bibliotecas seja compreensível ao leitor é importante descrever brevemente a instituição e suas características, que norteiam a parametrização e as ações de implantação. O Colégio Pedro II é uma instituição federal de ensino localizado no Estado do Rio de Janeiro, reconhecido pela excelência de ensino na educação básica, e atualmente possui quinze campi e um Centro de Referência em Educação Infantil. O Colégio Pedro II é uma instituição que completa 180 anos de idade no dia 02 de dezembro de 2017, e se equiparou a condição de IFES em 25 de junho de 2012 (BRASIL, 2012).

Por seu histórico de atuação na educação brasileira, possui uma Pró-Reitoria de Pós-Graduação, Pesquisa, Extensão e Cultura, constituída de programas de 
especialização, residência docente e um mestrado profissional, além do Centro de Documentação e Memória, com acervo de documentos físicos e digitais, de tipologias variadas. Esses locais também possuem bibliotecas para a salvaguarda de seus acervos, além da contínua procura por pesquisadores e acadêmicos, por vezes externos a comunidade escolar.

Assim, pode-se afirmar que as bibliotecas da instituição servem a um sistema heterogêneo de público-alvo (pesquisadores, professores, técnicos, alunos de educação básica e de pós-graduação), tipologia documental (de histórias em quadrinhos; literatura infantil, infanto-juvenil e brasileira/estrangeira; obras acadêmicas e documentos de memória) e objetivos (recreação, fomento, pesquisa escolar, pesquisa acadêmica) (FIGUEIREDO, 2015; FIGUEIREDO; TERRA, 2016).

As tentativas de automação do Sistema de Bibliotecas, Mediatecas e Salas de Leitura se iniciaram em 2000, sem sucesso. Houve testes com um software criado pela instituição e que não passou da versão beta até iniciar em 2010 testes com o Programa Biblioteca Livre - Biblivre ${ }^{3}$ mas, devido à complexidade institucional, percebeu-se a inviabilidade de uma implantação multicampi por meio desse software nacional. Neste momento, o Koha surge como uma proposta da DTI de software open source SIGB internacional para testes e a boa usabilidade e a variedade de recursos torna-se determinante para a adoção oficial em setembro de 2014.

\subsection{Software Koha}

O Koha Integrated Library Management System, ou simplesmente Koha, é um sistema de gerenciamento digital de bibliotecas totalmente operado via internet, considerado o primeiro sistema completo de gestão de bibliotecas e centros de documentação em formato de software livre e aberto (SHIESSL et al, p. 20, 2017).

O Koha é um software de licença open source destinado a automatizar as bibliotecas. Para isso, dispõe de uma interface administrativa composta de módulos para catalogação, cadastro de usuários, circulação e ferramentas como inventário, importação de registros em formato ISO, controle de periódicos (kardex) e relatórios. Para o usuário final, dispõe de um OPAC - Online Public Acess Catalog onde é possível ver o acervo multicampi e o histórico de circulação e pesquisa, além de permitir a inserção de listas, sugestões, tags e comentários das obras.

$\mathrm{Na}$ Comunidade Oficial do Koha ${ }^{4}$ existem alguns recursos que

3 Mais informações disponíveis em: http://biblivre.org.br/ Acesso em: 08 nov. 2017.

4 A Comunidade Oficial para download e mais informações estão disponíveis em: https://koha-community.org/ Acesso em: 06 nov. 2017 
permitem ao bibliotecário e/ou analista de sistemas compreenderem a proposta do software através da documentação disponível bem como realizarem uma avaliação das versões mais recentes instaladas em servidores demonstrativos, também chamados de demos, disponível em inglês, espanhol e francês, por empresas que vendem produtos e serviços vinculados ao Koha (ver ilustração 1 e 2). No mesmo local há os endereços para quem deseja contribuir diretamente para as melhorias do Koha, através das wikis de tradução e informando erros nas versões, chamados de bugs.
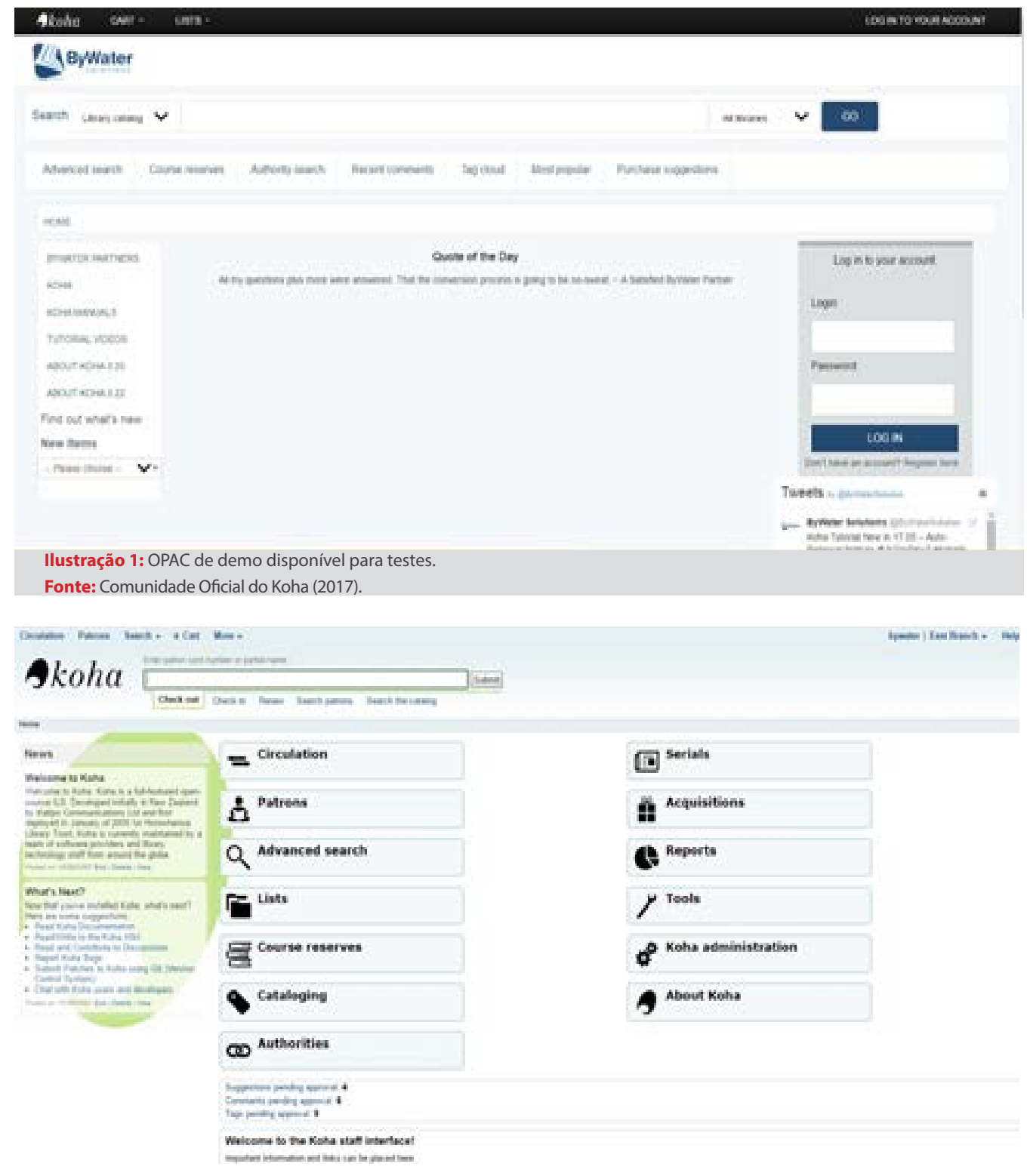

Ilustração 2: Versão administrativa demo disponível para testes Fonte: Comunidade Oficial do Koha (2017).

Antes do fomento do IBICT no Brasil havia iniciativas isoladas, como o uso do Koha por alguns campi do $\operatorname{IFSP}^{5}$ e o projeto de automação multicampi do

5 A automação desses campi foram repensadas quando houve uma proposta sistêmica, onde unificaria as bases a partir de um único software. Atualmente, as bibliotecas do IFSP utilizam o Software Pergamum, conforme endereço disponível em: http:// pergamum.biblioteca.ifsp.edu.br/. Acesso em: 06 nov. 2017. 
Sistema de Bibliotecas da Cidade de São Bernardo do Campo, iniciado em 2010 (FERNANDEZ, 2013). Atualmente, há mais bibliotecas que formalizaram o uso do Koha no Brasil e constam cinco instituições públicas na Wiki ${ }^{6}$ disponibilizada pelo IBICT: Biblioteca do Instituto Nacional de Pesquisas da Amazônia - INPA, Centro de Documentação e Pesquisa sobre Juventude e Políticas Públicas - CedocPPJ, Colégio Pedro II - Sistema de Bibliotecas, Mediatecas e Salas de Leitura, Biblioteca do Instituto Federal da Paraíba - IFPB, Sistema de Bibliotecas Municipais de Poços de Caldas ${ }^{7}$.

O cenário de implantação de um software como o Koha no Colégio Pedro II em 2014 era diferente do atual momento vivido pelas instituições públicas no Brasil. Como não tinha fomento no Brasil, e a comunidade internacional não oferecia manual de usuário em português, as dúvidas eram sanadas nos manuais em inglês e espanhol e com bibliotecários brasileiros que já tinham implantado esse SIGB em suas bibliotecas.

Houve dificuldades de testes, de parametrizar os módulos e emissão de relatórios pela maioria dos bibliotecários pela falta de manual e a dificuldade com o layout robusto que o Koha oferece. Também houve um esforço maior das equipes que realizaram testes e consenso sobre a robustez do software. Essas percepções induziram a demanda de oferecer cursos de gerenciamento de bibliotecas para as equipes, antes de implantar e dois anos depois, com a chegada de novos servidores.

\section{Alimentação das bases e uso do módulo circulação dois anos após implantação}

O ponto de partida para essa etapa pós-implantação pode ser marcada por duas ações: a migração de dados para o Koha produção da Biblioteca de PósGraduação, que utilizava o BibLivre e das bases da Biblioteca e das Mediatecas do Campus São Cristóvão III ${ }^{8}$, que criaram bases no Koha homologação; e por conseguinte a ministração de cursos para os servidores lotados nas bibliotecas e salas de leitura, bibliotecários, técnicos-administrativos, auxiliares de biblioteca e professores.

Após a migração e os cursos, senhas foram distribuídas conforme o perfil/ cargo do servidor. Na prática, foram consideradas as aptidões legais e a formação 
de cada pessoa, bibliotecários possuem senha com permissão para os módulos de circulação, ferramentas, relatórios e usuários, além de acesso à catalogação e autoridades, enquanto que os demais não possuem acesso os dois últimos recursos. Alguns bibliotecários também possuem permissão superlibrarian, que permite acesso irrestrito a todos os recursos.

Assim, começa a fase de alimentação das bases, que se iniciou de forma heterogênea: onde havia recursos humanos e equipamentos a inserção de dados do acervo ocorreu de forma imediata e regular, enquanto que em outros locais alguns problemas atrapalharam e/ou adiaram essa etapa, por motivos diversos: campus sem internet regular, em obras e em espaço provisório, setor sem computador, nenhum servidor disponível ou autorizado para entrar com dados.

Contudo, a estratégia adotada por parte das equipes em priorizar os livros mais procurados para a alimentação regular de dados gerando registros ${ }^{9}$, que por sua vez permite a inserção de itens ${ }^{10}$ de bibliotecas diversas (o que chamamos informalmente de pendurar o item), motivou as equipes com maiores dificuldades a buscar soluções junto às direções e chefias, para sanar os problemas que os impediam de iniciar esse trabalho. O envolvimento das equipes diminuiu o número de bases com poucos itens, e aumentou a regularidade da entrada de dados.

Ao realizar a inserção das obras mais populares no âmbito escolar, como livros da literatura infantojuvenil, e como um registro pode ter esses dados em diversas bibliotecas a alimentação das bases ocorre de modo exponencial, ou seja, após a obra ser registrada os demais apenas inserem os dados da biblioteca, que gera ganho de tempo e aumento de entrada de dados (segue na ilustração 3 um modelo de registro com diversos itens "pendurados"). A duplicidade de registros não é interessante para o usuário final, visto que aumenta o número de resultado na recuperação da informação e pouca relevância, conforme é possível observar na ilustração abaixo. Por outro lado, quando o registro aponta todas as bibliotecas que tem exemplares, é possível oferecer alternativas de empréstimo ao usuário e realizar mais empréstimos entre bibliotecas. Contudo, as regras vigentes da AACR são consideradas para a catalogação das obras, e livros com mesmo número de ISBN que são publicados em anos diferentes e/ou possuem edições diferentes são consideradas obras diferentes e possuem um registro para cada ano ou edição. 




Ilustração 3: Registro com exemplares em diversas bibliotecas.

Fonte: Catálogo Imperador (2017).

Após as duas turmas de capacitação concluírem o curso que permitiu o acesso à base definitiva em 2015, houve novo curso com os bibliotecários com o intuito de estudar a catalogação e discutir a adoção de entradas padronizadas e, em parceria com a Seção de Desenvolvimento Corporativo - SEDEC, a disponibilidade de uma nova turma de capacitação para os módulos básicos do Koha em 2017, destinado a novos servidores recém-lotados nas bibliotecas. O manual de entradas está em fase de discussão no Grupo de Trabalho de automação ${ }^{11}$.

Para que o cadastro de usuários fosse feito de forma mais célere, houve a migração dos dados dos alunos da educação básica e da pós-graduação do sistema da secretaria nos anos de 2015 e 2016, onde em torno de treze mil alunos tiveram seus dados inseridos no Koha e ativados mediante interesse no balcão. Os servidores (técnicos e professores) fazem o cadastro na hora e para número de carteirinha utilizam para acesso ao OPAC a Matrícula SIAPE e os estagiários e terceirizados o CPF. Em 2017 não foi possível realizar a migração de novos alunos pelo sistema da secretaria, o que obrigou as equipes a cadastrá-los no momento do atendimento no balcão, para fins de circulação.

Desde que se iniciou a alimentação das bases por parte das equipes houve a descoberta de outros recursos oferecidos pelo software que não estão em destaque nos recentes manuais publicados, mas são objetos descritos nas wikis da comunidade. Alguns recursos contribuem para aprimorar serviços em locais 
com instabilidade de internet, como o Plugin Koha Offline ${ }^{12}$, e outros atendem a demandas acadêmicas, como o módulo Bibliografias de Cursos e a opção no registro para analíticas de periódicos, dentro do registro da obra, para hospedar um item vinculado.

Do mesmo modo, a contínua alimentação das bases proporcionou melhorias nas planilhas para a realização de uma catalogação mais eficiente e adequada às demandas de cada biblioteca. Se no início havia uma única planilha traduzida e utilizada pelas equipes, após alguns meses houve a necessidade de criar planilhas específicas para periódicos, multimeios e objetos históricos. Como as planilhas são totalmente personalizáveis, algumas foram aprimoradas e receberam posteriormente novos campos e subcampos MARC.

\section{Análise da trajetória de implatanção do Koha}

Diante do exposto na seção anterior, é possível fazer uma análise dos últimos dois anos e pontuar quais foram os elementos que contribuíram para a realização ou não do Projeto de Automação do Sistema. O principal fator de êxito para a implantação e alimentação das bases das bibliotecas que observamos é o engajamento das equipes, leia-se bibliotecários, auxiliares de bibliotecas, técnicos e professores, bem como do maior envolvimento da Diretoria de Tecnologia da Informação nas etapas iniciais, para correção de erros que não era possível corrigir pela parametrização, como instalação no servidor ou de programas que fazem o Koha funcionar, como o de banco de dados e de linguagem.

$\mathrm{O}$ engajamento das equipes se traduz na participação das equipes nos cursos, no uso diário da lista de discussão por e-mail para sanar dúvidas, na busca por outras fontes de informação (blogs, redes sociais, artigos e livros) sobre o uso do Koha em outras instituições, e na aplicação do aprendizado em prática cotidiana nas bibliotecas. É recorrente também a sugestão de novos campos MARC na planilha mais utilizada, as trocas entre as equipes por telefone e quando algum módulo deixa de funcionar corretamente há uma notificação rápida aos gestores, que por sua vez informam pela lista de discussão aos demais colaboradores.

A motivação começou a se espalhar quando algumas bibliotecas começaram a disponibilizar a maior parte do seu acervo, de tal modo que o módulo 
de circulação começou a ser utilizado no cotidiano. As primeiras a fazerem uso foram a Biblioteca da Pós-Graduação e Biblioteca do Campus São Cristóvão III, inaugurada em julho de 2016. Em 2017 as Bibliotecas e Salas de Leitura dos Campi Centro, Humaitá II, Engenho Novo I, Engenho Novo II, Niterói, São Cristóvão II começaram a realizar empréstimos também ${ }^{13}$. Ainda existem unidades de informação que não iniciaram o uso do módulo circulação, mas que possuem essa etapa no planejamento para breve. É possível observar parte da visão sistêmica da entrada de dados através da ilustração 4.
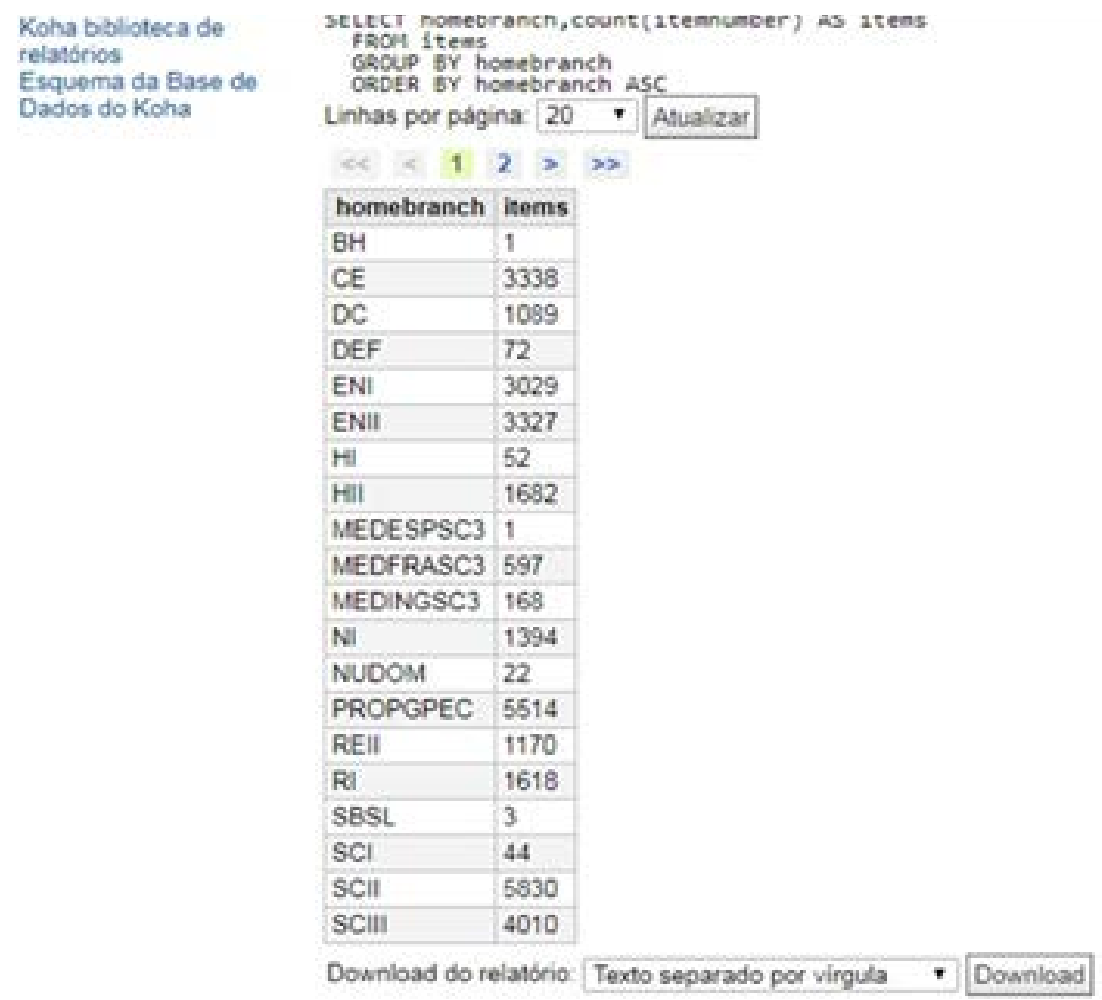

Ilustração 4: Relatório de Contagem de itens por biblioteca

Fonte: Catálogo Imperador (2017).

Por outro lado, a falta de recursos financeiros da Seção para compra de equipamentos de informática exclusivas para o Sistema de Bibliotecas, Mediatecas e Salas de Leitura não permitiu que a emissão de recibos e a leitura do código de barras fossem automatizados, porque não se adquiriu leitores de código de barras e impressoras para o balcão. As trocas e aquisições de novos computadores, do mesmo modo, ocorreram nos acordos firmados entre as Direções-Gerais de Campi e os setores, e não por verba própria da Seção de Bibliotecas. Isso significa que vários locais ainda não dispõem de terminais de consulta para usuários e computadores exclusivos para processamento técnico. 
Havia também a possibilidade de disponibilizar o catálogo na internet, para que os usuários tivessem como fazer uso do Koha em casa, mas por questões estruturais o OPAC está restrito ao acesso pela intranet, onde somente os IPs das máquinas dos campi conseguem encontrar o endereço onde o Catálogo está hospedado.

\section{Perspectivas para o futuro do Koha no Colégio Pedro II}

Apesar da experiência de automação do Sistema de Bibliotecas, Mediatecas e Salas de Leitura ser considerada vitoriosa por parte das equipes das bibliotecas e da Diretoria de Tecnologia de Informação - DTI, ainda existem diversas necessidades a serem sanadas, no que tange a parte tecnológica. É importante ressaltar que o Projeto de Automação do Sistema de Bibliotecas, Mediatecas e Salas de Leitura acompanhou a prerrogativa institucional de adotar soluções de software open source e livres/grátis para seus setores e serviços de tecnologia de informação, em cumprimento da Instrução Normativa 04/2014 (BRASIL, 2014).

A primeira necessidade a resolver é retomar a parceria com a DTI nas manutenções e atualizações para que o Koha não se torne obsoleto frente às outras versões disponibilizadas pela Comunidade Oficial. A versão utilizada no Colégio Pedro II é a mesma desde que foi instalada no servidor em dezembro de 2015, a versão 3.18, enquanto que já houve ao menos quatro novas atualizações de versão nesse período. Na prática, a falta de migração para novas versões inviabiliza o uso de novos recursos, a troca de saberes com outros profissionais nos fóruns internacionais e pode acarretar em maiores transtornos tecnológicos quando ocorrer a nova instalação pela grande diferença de estrutura entre as versões.

A percepção do Grupo de Trabalho que viabilizou o processo de automação compreende que a migração de usuários deve ser realizada ao menos uma vez por ano para cada segmento (educação básica e alunos de pós-graduação) e por questões administrativas nenhuma delas ocorreu em 2017. Os alunos da educação básica e da pós-graduação possuem calendários distintos e por isso é necessário que seja planejado previamente a migração para que o cadastro de novos usuários não se restrinja ao setor presencial de atendimento.

A falta de equipamentos também é um problema a ser sanado, visto que o espaço escolar apresenta horários de pico de atendimento, no qual o balcão 
de atendimento demora a realizar os procedimentos de circulação pela falta de leitor de código de barras, webcam e impressoras para emissão de recibos. No processamento técnico, há a necessidade de computadores exclusivos em alguns campi para que o material seja disposto no Catálogo Imperador e de scanner para que os registros possuam imagens das capas.

Uma barreira para os usuários que consideramos importante de resolver é a disponibilidade do Catálogo Imperador na internet. A DTI tem interesse em dispor um endereço para a consulta do acervo, e quando isso ocorrer acredita-se que o número de acessos bem como o uso da página do usuário para pesquisas e reservas deve aumentar consideravelmente.

Se no início havia a dificuldade técnica para análise do Koha como um software que resolvesse o perfil complexo que o Colégio Pedro II apresentava nas suas bibliotecas, e posteriormente a preocupação em conseguir que as equipes iniciassem o uso do Koha de modo cuidadoso, para que os erros fossem administráveis e resolvidos, após esses dois anos de efetivo uso busca-se mais recursos financeiros para a qualidade dos produtos e serviços e também a manutenção e melhorias no próprio Koha através da parceria com a DTI, além de aumentar a inserção de dados pelas bibliotecas que ainda não conseguiram progredir na automação de seu setor. Ainda assim, acredita-se que o Projeto logrou êxito na sua proposta e foi além do que se esperava inicialmente, bibliotecas, mediatecas e salas de leitura automatizadas e com o catálogo online.

\section{Referências}

BRASIL. Secretaria de Logística e Tecnologia da Informação. Instrução Normativa n. ${ }^{\circ}$ 04, de 12 de novembro de 2014. Governo Eletrônico, Brasília, DF, 28 mar. 2016. Disponível em:

https://www.governoeletronico.gov.br/documentos-e-arquivos/1\%20-\%20IN\%20 4\%20\%2011-9-14.pdf Acesso em: 08 nov. 2017.

BRASIL. Lei no 12.677, de 25 de junho de 2012, Dispõe sobre a criação de cargos efetivos, cargos de direção e funções gratificadas no âmbito do Ministério da Educação, destinados às instituições federais de ensino. Diário Oficial [da] República Federativa do Brasil, Poder Executivo, Brasília, DF, 26 jun. 2012. Disponível em: http://www.planalto.gov.br/ccivil_03/_ato2011-2014/2012/lei/ L12677.htm Acesso em: 07 out. 2014.

COLÉGIO PEDRO II. Página oficial. Disponível em: http://www.cp2.g12.br 
Acesso em: 26 set. 2017.

COLÉGIO PEDRO II. Portaria n ${ }^{\circ} 4905$, de 14 de setembro de 2014, constitui Grupo de Trabalho para a Automação das Bibliotecas e Salas de Leitura do Colégio Pedro II. Facta, Rio de Janeiro, n. 341, 17 set. 2014.

FERNANDEZ, Rafael Saad. O uso de softwares livres na gestão pública de acervos informacionais: o caso do Koha nas bibliotecas de São Bernardo do Campo. Inf. Inf., Londrina, v. 18, n.2, p. 231 - 248, maio/ago., 2013. Disponível em: http:// www.uel.br/revistas/uel/index.php/informacao/article/view/16174 Acesso em: 28 ago. 2017.

FIGUEIREDO, Márcia Feijão de. Análise do software Koha no Colégio Pedro II: Um relato de experiência. RDBCI: Revista Digital de Biblioteconomia e Ciência da Informação, Campinas, SP, v. 13, n. 3, p. 653-665, set. 2015. ISSN 1678-765X. Disponível em: https://periodicos.sbu.unicamp.br/ojs/index.php/rdbci/article/ view/2125 Acesso em: 28 ago. 2017. doi:http://dx.doi.org/10.20396/rdbci. v13i3.2125

FIGUEIREDO, Márcia Feijão de; TERRA, Isabela Cristina Teles. A implantação do Koha no Colégio Pedro II em quatro atos. Revista ACB, Florianópolis[S.l.], v. 21, n. 1, p. 253-264, mar. 2016. ISSN 1414-0594. Disponível em: https://revista. acbsc.org.br/racb/article/view/1154 Acesso em: 28 ago. 2017.

INSTITUTO BRASILEIRO DE INFORMAÇÃO EM CIÊNCIA E TECNOLOGIA. Koha. In.: Wiki IBICT. Disponível em: http://wiki.ibict.br/index.php/Koha Acesso em: 09 nov. 2017.

KOHA. About Koha: history. 2017. Disponível em: https://koha-community.org/ about/history/ Acesso em: 06 nov. 2017.

SHIESSL, Ingrid [et el.]. GUIA do usuário do Koha. Brasília: IBICT, 2017. Disponível em: http://livroaberto.ibict.br/handle/123456789/1064 Acesso em: 07 nov. 2017. 